\title{
UM DIÁLOGO SOBRE CURRÍCULOS, CULTURA DIGITAL E UMA AULA NO 1ㅇ ANO DO ENSINO FUNDAMENTAL
}

\author{
Ivanete Fátima Blauth ${ }^{1}$ \\ Bárbara Drielle Roncoletta Corrêa ${ }^{2}$ \\ Suely Scherer ${ }^{3}$
}

\begin{abstract}
RESUMO
O objetivo, com este artigo, é apresentar resultados de uma pesquisa que analisou e problematizou currículos prescritos e currículos em ação em uma escola de Ensino Fundamental a partir de movimentos de integração da tecnologia digital ao currículo escolar. Para tanto, partimos de estudos sobre princípios da complexidade para problematizar questões que dizem respeito à cultura digital e ao currículo escolar. Os dados analisados são provenientes de uma pesquisa realizada em uma escola pública do município de Campo Grande (MS), com quatro professoras dos anos iniciais em uma proposta de formação continuada em serviço durante dois anos. Neste artigo serão trazidas para diálogo apenas informações sobre um currículo prescrito para o 10 ano do Ensino Fundamental, vigente nesta escola em 2017, e uma narrativa sobre um currículo vivenciado em sala de aula, com o uso da internet, por uma professora e seu grupo de alunos. Com base nas análises, é possível considerar que o currículo prescrito para essa escola era orientado por uma fragmentação de disciplinas e conteúdos, e que o currículo posto em ação por essa professora e seus alunos, ao integrar a internet à aula, configurou-se em um currículo com características transdisciplinares, um currículo complexo.
\end{abstract}

Palavras-chave: Currículo. Cultura digital. Complexidade. Anos iniciais.

\section{A DIALOGUE ABOUT CURRICULUMS, DIGITAL CULTURE AND A CLASS IN THE FIRST YEAR ELEMENTARY SCHOOL}

\begin{abstract}
The objective, with this article, is to present results of a research that analyzed and problematized prescribed curricula and curricula in action in an elementary school, from integration's movements of digital technology to the school curriculum. To this end, they served as a contribution studies on principles of complexity to problematize issues about digital culture and the school curriculum. The data analyzed come from a survey carried out in a public school in Campo Grande, MS, with four teachers from the initial years, with a proposal of continuous training in service for two years. In this article, only information about a prescribed curriculum for the first year of elementary school corresponding to the year 2017, and a narrative about a curriculum in use in the classroom, using the Internet, by a teacher and her group of students. Based on the analysis, is possible to consider that the prescribed curriculum for this school oriented by a fragmentation of disciplines and contents, and that the curriculum put in action by this teacher and its students, when integrating the Internet to the class, it was configured complex, given its transdisciplinary characteristics.
\end{abstract}

Keywords: Curriculum. Digital culture. Complexity. Elementary school.

RECEBIDO EM: 18/12/2019

ACEITO EM: 20/4/2020

\footnotetext{
1 Autora correspondente. Universidade Federal de Mato Grosso do Sul - UFMS. Av. Costa e Silva, s/no - Bairro Universitário. CEP 79070-900. Campo Grande/MS, Brasil. http://lattes.cnpq.br/9507502336775818. https://orcid.org/0000-0003-0533-2808. ivanetefatima@hotmail.com

2 Universidade Federal de Mato Grosso do Sul - UFMS. Campo Grande/MS, Brasil. http://lattes.cnpq.br/1630527362670013. https://orcid. org/0000-0001-8869-7145

3 Universidade Federal de Mato Grosso do Sul - UFMS. Campo Grande/MS, Brasil. http://lattes.cnpq.br/6812065936018405. https://orcid. org/0000-0002-2213-3803
} 


\section{UMA BREVE CONTEXTUALIZAÇÃO}

Cultura Digital e escola, currículo prescrito e currículo em ação, fragmentação e transdiciplinaridade, planejado e inesperado, conhecido e emergente, documento e ação... Palavras e sentidos antagônicos ou complementares? Ou antagônicos e complementares? Se existem mecanismos para encurtar a distância entre esses e tantos outros pares, como podemos articular os opostos, olhando-os de forma integrada e não excludentes no espaço da escola? Por exemplo, quando pensamos em currículo pela lógica da complexidade temos nem só documento, nem apenas ação, mas documento e ação, que se constituem em um terceiro elemento constituído de documentos e ações. A proposta é articular esses pares, e outros pares, tríades..., discutindo e problematizando possibilidades de currículos em ação em diferentes espaços escolares.

Com este artigo temos por objetivo apresentar resultados de uma pesquisa em que se analisou e problematizou currículos prescritos e currículos em ação em uma escola de Ensino Fundamental, a partir de movimentos de integração da tecnologia digital ao currículo escolar. As informações da pesquisa foram produzidas em uma escola pública do município de Campo Grande/MS, na qual desenvolvemos uma pesquisa, durante dois anos (2017 e 2018), sob o título "Integração de Tecnologias Digitais ao Currículo dos Anos Iniciais do Ensino Fundamental: Desafios para/na Inovação" ${ }^{4}$. Neste artigo, articulado às discussões teóricas, dialogaremos sobre o currículo prescrito para o 10 ano do Ensino Fundamental dessa escola no ano de 2017, e sobre uma narrativa de um currículo vivenciado por uma professora e seu grupo de alunos ao integrar tecnologias digitais.

A narrativa é de uma professora participante da pesquisa, que relatou, em um dos encontros de planejamento ${ }^{5}$, uma prática desenvolvida com sua turma de alunos do 10 ano do Ensino Fundamental na escola lócus da pesquisa. Essa prática pode conduzir a uma problematização do currículo prescrito em relação ao currículo posto em ação, e evidenciar que nesse currículo em ação podemos vivenciar a complexidade, desde que não fiquemos presos aos currículos prescritos, pensados, muitas vezes, de forma igual para todos. Desse modo, dentre outras coisas, problematizamos o reducionismo e a dualidade

[...] tentando evitar a prescrição de um "currículo uniforme" igual para todos, evitando-se assim um currículo pasteurizado, homogeneizado, aquela coisa de "tamanho único" que serve para todos, esquecendo que as situações educacionais, bem como seus objetos de estudo, implicam processos de natureza complexa, portanto, diferenciados, auto-eco-organizadores, emergentes, imprevisíveis e sujeitos ao acaso (MORAES, 2010, p. 3).

Para orientar este estudo, bem como a análise de informações produzidas na pesquisa, recorremos a princípios da complexidade, que, de modo geral, contrapõem-se à fragmentação do conhecimento, à dicotomia das dualidades e propõem outra maneira

\footnotetext{
4 Pesquisa financiada e aprovada na Chamada Fundect/Capes N 11/2015 EDUCA MS CIÊNCIA E EDUCAÇÃO BÁSICA. 5 O relato da professora foi feito oralmente durante o encontro, com posterior transcrição realizada pelos autores deste artigo.
} 
de se pensar os problemas contemporâneos, promovendo uma relação de interdependência entre os acontecimentos, ações e interações que acontecem na vida. Com olhares complexos buscamos, com esta pesquisa, compreender a realidade de forma menos redutora possível, indo ao encontro da afirmação de Moraes (2010, p. 6): "um sistema organizado não exclui a diversidade, mas a incorpora". Da mesma forma, a partir da narrativa da professora buscamos representar um olhar, uma interpretação sobre determinada situação, orientados pelos estudos de Rodrigues, Almeida e Valente (2017, p. 64): "as narrativas são uma forma de contar, uma maneira de lembrar, um jeito de registrar as memórias, reviver as histórias e (re)significar o vivido".

Inicialmente apresentaremos nossas compreensões sobre tecnologias digitais, cultura digital, currículo e complexidade; em seguida discutiremos currículo prescrito e currículo em ação a partir da prática de uma professora; para finalizar, teceremos algumas considerações decorrentes da pesquisa realizada e dados analisados.

\section{TECNOLOGIAS DIGITAIS E CULTURA DIGITAL}

Como seres humanos podemos ser considerados seres culturais, pois desde o nascimento recebemos influências externas, vivenciando a cultura de nossos pais e pessoas próximas, configurando-nos e (re)configurando-nos nas relações com as pessoas e o meio em que vivemos. Morin (2003, p. 40) considera o ser humano um "ser complexo", pois se revela um "ser, ao mesmo tempo, totalmente biológico e totalmente cultural. 0 cérebro, por meio do qual pensamos, a boca, pela qual falamos, a mão, com a qual escrevemos, são órgãos totalmente biológicos e, ao mesmo tempo, totalmente culturais".

Somos seres culturais no sentido de que somos incompletos e a maioria das nossas ações (falar, andar, alimentar-nos, escrever, pensar) são decorrentes do que aprendemos na interação com o meio e as pessoas com quem convivemos. Nessas relações de dependência vamos nos constituindo como seres integrantes dessa cultura, que se reconfigura conforme as necessidades e o passar do tempo, ajudando, inclusive, a produzi-la.

Morin (2003, p. 47) considera que "é preciso pensar a palavra 'cultura', em seu sentido antropológico: uma cultura fornece os conhecimentos, valores, símbolos que orientam e guiam as vidas humanas". Nessa mesma direção, Heinsfeld e Pischetola (2017, p. 1352) afirmam que "toda ação humana significa algo e participa de alguma forma nas interações sociais: a cultura é parte das práticas sociais, está vinculada à sociedade, mas não equivale à totalidade da sociedade". Ou seja, como seres humanos praticamos ações, interagimos com outras pessoas, assumimos responsabilidades e compromissos em uma sociedade que, para se constituir e ser constituída, depende, dentre outras coisas, das interações e das práticas sociais.

Essas práticas sociais sofrem alterações de acordo com o tempo e as necessidades dos seres humanos em determinado contexto. A partir dessas necessidades, também se modificam os modos de vida em sociedade. O ser humano foi criando ou se adaptando aos objetos técnicos de acordo com as necessidades de cada época (desde as armas feitas com pedras e ossos, na Antiguidade, até as máquinas e equipamentos mais modernos da atualidade). Essa evolução configurou-se como uma "reestruturação da sociedade"; hoje, vivemos uma era (da conectividade, ubiquidade, interatividade) em 
que as tecnologias digitais (computadores, tablets, celulares ...), quando conectadas à internet, permitem a reconfiguração de muitas atividades do cotidiano, como comunicar-se, estudar, ler, comprar e vender... independentemente de hora e lugar.

Embora ainda existam pessoas que não "estão conectadas" às tecnologias digitais, podemos afirmar que grande parte da população "é conectada" à cultura digital proveniente do uso de tecnologias (meios eletrônicos), e que, segundo Heinsfeld e Pischetola (2017, p. 1.354), foi "pensada como um marcador cultural, que envolve tanto os artefatos digitais quanto sistemas de significação e comunicação distintos, capazes de descrever o modo de vida contemporâneo".

Com esse modo de vida, ainda de acordo com as autoras, "superamos o 'estar conectado', alcançando o patamar do 'ser conectado'" (HEINSFELD; PISCHETOLA, 2017, p. 1.350), haja vista que grande parte das nossas ações diárias são dependentes da conectividade e interações que as tecnologias digitais possibilitam. Esse fato, para muitas pessoas, não é mais novidade, uma vez que já está naturalizado. Inclusive, se observarmos os "nativos digitais" podemos perceber que, desde pequenos, eles usam com facilidade e integram as tecnologias digitais à sua vida, produzindo, com elas, diversos saberes. Mencionemos, ainda, os "imigrantes digitais" ${ }^{\text {, }}$ que também fazem uso, interagem, produzem e se comunicam a partir da "linguagem digital" (que, muitas vezes, é traduzida nas telinhas em símbolos, abreviações, áudios, diferentes animações ou vídeos), além de mesclarem esse uso com aquelas produzidas em meios mais analógicos.

Em algumas escolas já se observam investimentos na compra de tecnologias digitais (computadores, tablets, lousas digitais) e, inclusive, no acesso à internet. Nesse sentido, tendo em vista movimentos de cultura digital, seria interessante pensar em possibilidades de integrar essas tecnologias aos currículos, aos processos educacionais, pois, conforme afirma Kenski (2012, p. 43), "educação e tecnologias são indissociáveis"; na educação se pode produzir movimentos diferenciados, que acompanhem a evolução das tecnologias e atendam também a necessidade da sociedade em geral. É evidente que ter acesso a tecnologias com conexão à internet não é garantia de que elas sejam integradas ao currículo, tampouco que sejam utilizadas nas aulas com o intuito de favorecer a aprendizagem dos alunos em movimentos imbricados aos de uma cultura digital. Essa hipótese pode ser confirmada quando observamos que professores e alunos, que produzem cultura digital fora das escolas, são considerados, em sua maioria, "seres conectados", enquanto no ambiente escolar são considerados seres que "estão conectados", e, em alguns momentos de aula, até "desconectados".

Este fato convida-nos a refletir sobre o que tem sido feito nas escolas para possibilitar uma relação de interdependência entre a cultura digital e os processos educacionais. Como essa cultura digital poderia estar integrada aos processos de ensino e de aprendizagem? E, ainda, de que forma os currículos poderiam ser (re)pensados para

O termo caracteriza os seres humanos que passaram a conviver, dia a dia, com a presença das tecnologias digitais, e, aos poucos, se (re)inventam ao utilizá-las nas suas atividades cotidianas. 
compor um contexto complexo, como é o das escolas, que recebem os alunos "nativos digitais7 "? Como problematizar ações da cultura digital em currículos vivenciados nas escolas? E tantas outras questões.

A partir dessas reflexões, é importante discutir o que se compreende por currículo e sua relação com a complexidade.

\section{CURRÍCULOS E PRESSUPOSTOS DA COMPLEXIDADE}

Nos dias atuais, em razão das mudanças culturais vivenciadas pela sociedade, (re) pensar os processos educacionais torna-se quase uma necessidade recorrente, haja vista que a estrutura escolar parece não acompanhar essas evoluções culturais, políticas e sociais. Nesse cenário, acreditamos que um possível caminho para incitar algumas discussões seja pensar em mudanças no "currículo", que não pode/deve envolver apenas a elaboração de documentos, mas a problematização/ações produzida(s) nas escolas, ao considerar a complexidade e a dinamicidade de quem participa de processos escolares.

Moraes (2010), fundamentada em Silva (2005), defende que

[...] currículo é lugar, espaço, território. É texto, discurso e documento. Mas, um documento que revela determinada identidade. Em realidade, currículo é o documento de identidade de cada escola, revelador da complexidade de seu percurso, de suas opções teóricas, de seus objetivos, de suas metas, princípios e metodologias trabalhadas. Revela também a visão de sujeito e de mundo compartilhada por determinada comunidade educacional, o conjunto de princípios que norteia suas ações, independente da área de interesse ou da especialidade de cada professor (p. 4).

Nessa perspectiva, essa autora considera que currículos prescritos são guias que orientam a elaboração do projeto educacional da escola, "um documento que traz uma rede de referências importantes, a partir da qual se tenta organizar o trabalho educacional e contribuir para a formação do sujeito aprendente, tendo em vista a construção de uma sociedade democrática" (MORAES, 2010, p. 4).

Um currículo prescrito geralmente prevê conteúdos, objetivos, metodologias a serem trabalhadas durante um ano letivo, em disciplinas. Muitas vezes é organizado em documentos orientadores, como as Orientações Curriculares, a Base Nacional Comum Curricular (BNCC), o Projeto Político Pedagógico (PPP)..., geralmente embasados em documentos como a Lei de Diretrizes e Bases (LDB), os Parâmetros Curriculares Nacionais (PCNs), as Diretrizes Curriculares,...

Currículo, entretanto, é muito mais do que documentos; um currículo implica, também, movimentos, ações, produções... geradas e desenvolvidas na escola por seres culturais, por subjetividades tantas e diversas que agem e interagem em cada pessoa e espaço-tempo que é uma escola; por isso, os currículos estão sempre sendo construídos. Não há um currículo na escola; há currículos, que se autoeco-organizam nas relações educacionais, políticas e sociais!

Esse termo foi utilizado por Prensky (2001) para se referir a crianças e adolescentes que nasceram e cresceram em contato com tecnologias digitais em seu dia a dia. 
De acordo com Almeida e Valente (2011), currículo pode ser compreendido como uma construção social que

[...] integra os conteúdos da cultura selecionados previamente segundo determinadas intenções para uso em situações de ensino e aprendizagem, com as concepções, valores, crenças, experiências, recursos, tecnologias, estratégias mobilizadas na situação pedagógica (p. 14).

Nesse sentido, pensamos em currículos complexos que contemplem interesses educacionais e sociais, envolvidos com a cultura e o contexto no qual seus sujeitos interagem. Currículos que se orientam pela formação de seres humanos, considerando-os seres pensantes (atores e autores) implicados em um determinado contexto cultural, de forma recursiva ${ }^{8}$ e hologramática ${ }^{9}$, construtores e (re)construtores de seus conhecimentos e da sociedade em que vivem, que se autoeco-organizam ${ }^{10}$.

Almeida e Valente (2011) complementam que

o currículo se desenvolve na reconstrução desse conteúdo prescrito nos processos de representação, atribuição de significado e negociação de sentidos, que ocorrem primeiro no momento em que os professores elaboram o planejamento de suas disciplinas levando em conta as características concretas do seu contexto de trabalho, as necessidades e potencialidades de seus alunos, suas preferências e seu modo de realizar o trabalho pedagógico. Em seguida o currículo é ressignificado no momento da ação quando os professores alteram o planejado no andamento da prática pedagógica conforme as demandas emergentes de seus alunos, o seu fazer e refletir na ação (p. 14).

Assim sendo, entendemos que currículo é produzido também na ação, a partir de interações com o meio, com o outro, que, a todo momento, é (re)construído social, histórica, política e culturalmente,...; há um currículo planejado, mas que é aberto e flexível, que pode se transformar ao ser vivenciado, a depender de como os sujeitos que o vivenciam lidam com o acaso, com o inesperado, com as situações que acontecem no cotidiano. Currículo pode ser, também, um caminho a ser construído, repleto de bifurcações, que também envolve sentimentos, subjetividade, afeto, e que, constantemente, pode ser transformado, autoeco-organizado.

Desse modo, consideramos importante (re)pensar essas possibilidades que vão além do currículo proposto/praticado na maioria das escolas. Um currículo que considera necessidades de cada membro do grupo e da própria sociedade; que pode integrar objetos técnicos ao ambiente escolar, conforme despontam nos movimentos de rees-

3 O princípio da recursividade nos mostra que o movimento de aprendizagem, de organização, de pensamento, ao entrar em interação com o outro, quando retorna não está do mesmo jeito, mas em patamar superior, pois estamos em constante transformação e organização.

9 O princípio hologramático remete-nos à articulação dos pares binários: simples-complexo, parte-todo, unidade-diversidade, etc., e nos ensina que dentro das partes está o todo e dentro do todo estão as partes (MORIN, 2014). É preciso saber respeitar as identidades e não tentar reduzir a uma soma, pois é sempre mais que essa soma.

${ }^{10}$ Compreendemos a autoeco-organização como a ação de o indivíduo (ser vivo) autoproduzir-se o tempo todo nas relações que estabelece com o outro e com o meio. Esse processo não se dá de maneira isolada; pelo contrário, há uma constante relação de dependência entre os pares. A autoeco-organização acontece pelo falo de que todo ser vivo pode ser considerado também um sistema autopoiético, ou seja, que tem a capacidade de se autoconstruir, se auto-organizar. 
truturação da cultura; um currículo menos fragmentado em disciplinas, que considera diferentes realidades e contextos, afinal o "retalhamento das disciplinas torna impossível apreender 'o que é tecido junto', isto é, o complexo, segundo o sentido original do termo" (MORIN, 2003, p. 13-14).

Assim, pode-se pensar que currículo também é complexidade, e "[...] nos revela a incompletude dos processos, que nos mostra a incompletude do conhecimento e a incompletude do ser aprendente que somos" (MORAES, 2010, p. 6). Afinal, todavia, o que vem a ser a complexidade? Segundo Morin (2003, p. 14), a complexidade existe quando os componentes "que constituem um todo (como o econômico, o político, o sociológico, o psicológico, o afetivo, o mitológico) são inseparáveis e existe um tecido interdependente, interativo e inter-retroativo entre as partes e o todo, o todo e as partes". Na tentativa de especificar um pouco mais, sem reduzir o complexo ao simples, trazemos a intepretação de Moraes (2010), que compreende a complexidade como

Uma tessitura comum que coloca como sendo inseparavelmente associados o indivíduo e o meio, a ordem e a desordem, o sujeito e o objeto, o professor e o aluno e todos os demais tecidos que regem os acontecimentos, as ações e as interações que tecem a trama da vida (MORAES, 2010, p. 5).

É possível perceber que na complexidade há uma relação constante de dependência, uma vez que estes pares binários são integrantes de uma mesma realidade e que, portanto, não faz sentido pensar este universo de forma reducionista, isto é, o isso ou o aquilo, mas uma tensão que sobrevive no e... e... e... O sujeito (ser vivo) habita diferentes ambientes e em cada um deles interage com inúmeras pessoas e fenômenos, incorporando, nesses movimentos, novos conhecimentos. Nesse sentido, ao invés de excluir possibilidades, precisamos pensar de forma a inclui-las, ou seja, o isso, o aquilo, e mais esse, e mais aquele, e...

Como educadores, podemos pensar em possibilidades de fazer com que esses currículos produzidos na escola, na ação, evitem, ao máximo, a essencialidade, a delimitação. Voltamos nossos olhares ao acontecimento, às múltiplas realidades e subjetividades, que, muitas vezes, acabam por fugir às previsões, ao planejamento, ao controle, tendo em vista que "[...] Conscientes ou não, somos construtores, criadores e recriadores das propostas curriculares no momento de sua materialização em sala de aula" (MORAES, 2010, p. 7).

Para problematizar e analisar questões sobre currículo e cultura digital, escolhemos, para a pesquisa, alguns caminhos metodológicos que apresentamos a seguir.

\section{ESCOLHAS METODOLÓGICAS}

Neste artigo apresentamos e problematizamos ações previstas em um currículo prescrito para o 10 ano do Ensino Fundamental e, também, um movimento de currículo vivenciado, no qual uma professora utilizou a internet em sala de aula com seus alunos. Para tanto, partimos de estudos teóricos sobre a teoria da complexidade, estabelecendo relações desta com os currículos e a cultura digital. 
As informações analisadas são provenientes de uma pesquisa desenvolvida em uma escola pública do município de Campo Grande - MS. Essa investigação constituiu-se a partir de uma ação de formação continuada ${ }^{11}$ de professores para a integração de tecnologias digitais ao currículo dos anos iniciais do Ensino Fundamental, da qual participavam quatro professoras que atuam com alunos dos anos iniciais nessa escola.

Os dados da pesquisa foram produzidos a partir das seguintes fontes: entrevista inicial com as professoras (fevereiro de 2017), áudios e vídeos gravados nos encontros presenciais com cada professora (os encontros de planejamento e avaliação aconteceram durante dois anos, quinzenalmente, na escola) e em algumas aulas observadas, diários elaborados por pesquisadores, tanto de observação de aulas quanto de encontros de planejamento e avaliação de aulas, e diálogos pelo WhatsApp. Todos esses materiais foram produzidos na escola, com as professoras, com seus grupos de alunos, durante dois anos (2017 e 2018).

Para este artigo selecionamos, para análise, recortes a partir do que é previsto nas Orientações Curriculares para o 10 ano (currículo prescrito) pela rede municipal de Campo Grande/MS, e uma breve narrativa de prática docente realizada em sala de aula por uma das professoras participantes da pesquisa (currículo em ação), no ano de 2017. $\mathrm{Na}$ análise, lançamos olhares em/para alguns recortes selecionados do currículo prescrito, problematizando-os ao discutir um currículo em ação.

A narrativa da professora (pedagoga que atua com o 10 ano do Ensino Fundamental) foi selecionada a partir do registro de uma das reuniões de planejamento (uma das ações propostas e desenvolvidas durante a formação continuada da qual ela participou), em que ela relatou (relato oral que, posteriormente, foi transcrito) uma prática realizada durante o ano de 2017 na disciplina de Geografia. Para essa aula, foi planejado o uso do notebook da professora (com acesso à internet), articulado ao projetor multimídia, com o objetivo de discutir o endereço dos alunos; a professora solicitou, na aula anterior, que os alunos trouxessem anotado o nome da rua, do bairro e o número da casa onde moravam. A narrativa feita por essa professora será apresentada e analisada a seguir.

Para essa análise são apresentados recortes do referido currículo prescrito, que é ressignificado na ação e nas interações entre a professora e alunos. Esses dados foram analisados com base nos pressupostos da complexidade.

\footnotetext{
${ }^{11}$ Esta ação de formação continuada em serviço de professores foi proposta por pesquisadoras da UFMS, cujo objetivo foi problematizar movimentos de integração de tecnologias digitais ao currículo dos anos iniciais do Ensino Fundamental. Tivemos a participação, por adesão, de quatro professoras de uma Escola Municipal de Campo Grande - MS. Esta ação de formação constituiu-se de encontros quinzenais e alguns mensais, nos quais, em parceria com as professoras, planejávamos e avaliávamos ações desenvolvidas em sala de aula durante o ano letivo. Tais planejamentos destinavam-se às disciplinas de Língua Portuguesa, Matemática, História e Geografia, tendo em vista a integração de tecnologias digitais.
} 


\section{TECITURAS COMPLEXAS ENTRE UM CURRÍCULO PRESCRITO PARA O 1 ANO E UM CURRÍCULO VIVENCIADO}

Nossa análise inicia-se com olhares voltados ao currículo proposto para essa escola em 2017, a saber, "Orientações curriculares do Ensino Fundamental - 1ㅇa ao 5o ano". Nesse documento, que é proposto no município de Campo Grande ${ }^{12}$ como orientador das práticas pedagógicas dos professores, foi possível observar que há vários desmembramentos, por exemplo, as turmas são isoladas em "anos"; para cada ano são propostas disciplinas separadas; e, ainda, para uma disciplina há segregações entre os conteúdos a cada bimestre. Esses movimentos vão ao encontro de afirmações de Morin (2003):

Na escola primária nos ensinam a isolar os objetos (de seu meio ambiente), a separar as disciplinas (em vez de reconhecer suas correlações), a dissociar os problemas, em vez de reunir e integrar. Obrigam-nos a reduzir o complexo ao simples, isto é, a separar o que está ligado; a decompor, e não a recompor; e a eliminar tudo que causa desordens ou contradições em nosso entendimento (p. 15).

Considerar o currículo apenas sob esse ponto de vista causa certo desconforto, uma vez que as crianças, desde pequenas (geralmente matriculadas no 10 ano com 6 anos de idade), são submetidas a essa vivência; expostas a "[...] tais condições, as mentes jovens perdem suas aptidões naturais para contextualizar os saberes e integrá-los em seus conjuntos" (MORIN, 2003, p. 15). Ou seja, essas situações, muitas vezes, fazem com que as crianças se adaptem a uma segregação que não lhes é natural. A Figura 1 evidencia esse tipo de fragmentação.

Figura 1 - Distribuição de disciplinas

ORIENTAÇOESS CURRICULARES
T'ANO
UINGUA PORTUGUESA
MATEMATICA
HISTORIA
GEOGRAFIA
CIÉNCIAS

LINGUA PORTUGUESA $-1^{\circ}$ ANO

\begin{tabular}{|c|c|c|c|}
\hline B.M. & & & QUETIYOS \\
\hline \multirow[b]{3}{*}{$1^{*}$} & ORALIDADE & $\begin{array}{l}\text { Produçáo e } \\
\text { Expressbo oral }\end{array}$ & 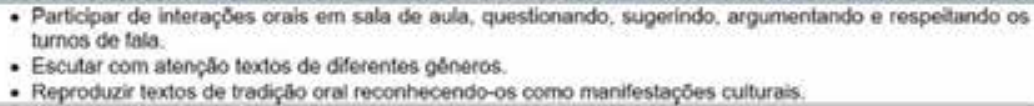 \\
\hline & \multirow{2}{*}{$\begin{array}{l}\text { ANALISE E } \\
\text { REFLEXAO } \\
\text { SOBREA } \\
\text { LINGUA }\end{array}$} & Base altabetica & 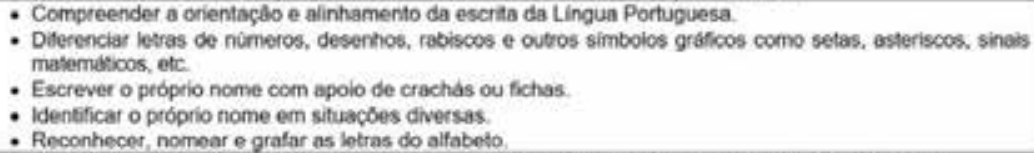 \\
\hline & & $\begin{array}{l}\text { Discursividade, } \\
\text { textualidade e } \\
\text { nomatividade }\end{array}$ & 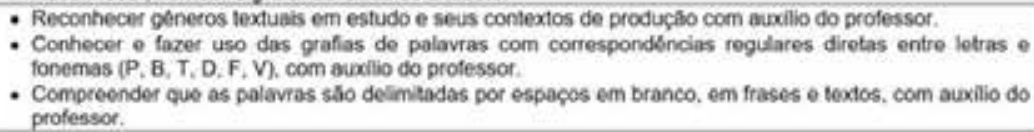 \\
\hline
\end{tabular}

Fonte: CAMPO GRANDE-MS, 2016, p. 3.

\footnotetext{
12 Em relação aos conteúdos, é importante ressaltar que esse era o principal documento orientador das práticas pedagógicas das professoras. Além deste, o PPP também era consultado para direcionar algumas ações previstas. 
Observamos que na proposta curricular para o $1^{\text {ㅇ }}$ ano sugere-se várias disciplinas separadamente, e cada uma delas é subdividida em eixos, conteúdos e objetivos que devem ser estudados/cumpridos durante os bimestres do ano letivo. Nesse sentido, chama a atenção o fato de que, nessa escola, as disciplinas de Língua Portuguesa, Matemática, História e Geografia são trabalhadas, no 10 ano, por uma mesma professora regente em horários predefinidos pelos gestores da escola, com aulas de 50 minutos; as outras disciplinas são ministradas por professores da área específica: Artes, Educação Física e Ciências.

Assim, em um período diário de aula uma criança pode ter aulas de Língua Portuguesa (um tempo de 50 minutos), História (um tempo) e Matemática (dois tempos), o que, de certo modo, pode causar dificuldades para essa criança, uma vez que o processo exige guardar um caderno e pegar outro, fechar e abrir as "gavetinhas" das disciplinas, das ideias, dos pensamentos, das produções, dos interesses, movimentos que podem destoar de seu ritmo e maneira de aprender, de sua (con)vivência cotidiana fora da escola.

Morin (2014, p. 176-177), em um de seus estudos, discute que "a ambição da complexidade é prestar contas das articulações despedaçadas pelos cortes entre disciplinas, entre categorias cognitivas e entre tipos de conhecimentos". Se isso é possível, o que pode ser feito diante da incompletude e da incerteza dos movimentos que despontam? Que ideias podem ser válidas para modificar essa segregação, principalmente quando pensamos na educação de crianças? Como pensar em um currículo prescrito que dê conta das articulações inter/entre disciplinas? Respostas, não temos... apenas inquietações, muitas inquietações!

Outro ponto que chama a atenção é que muitas crianças, desde que iniciam suas atividades escolares, são "convidadas" a seguir uma linearidade de ações, ou seja, são inseridas em turmas nas quais a maioria das crianças são da mesma faixa etária, mas, depois, aprendem que as disciplinas, assim como os conteúdos, são trabalhadas separadamente, isoladas, sem conexão entre si e em tempos distintos. Os problemas que emergem no cotidiano da sala de aula poderiam ser explorados e desvendados de forma interdisciplinar, quiçá transdisciplinar, integrados uns aos outros. Na maioria das situações, contudo, aguardam um certo horário e/ou disciplina, um determinado conteúdo, que propiciem a discussão e a problematização dessas questões emergentes; no entanto, muitas vezes, elas acabam ignoradas ou esquecidas! Com essa disjunção de saberes, a produção de conhecimento vai sendo podada e moldada, desde muito cedo, no ambiente escolar. De fato,

[...] a hiperespecialização impede de ver o global (que ela fragmenta em parcelas), bem como o essencial (que ela dilui). Ora, os problemas essenciais nunca são parceláveis, e os problemas globais são cada vez mais essenciais. Além disso, todos os problemas particulares só podem ser posicionados e pensados corretamente em seus contextos; e o próprio contexto desses problemas deve ser posicionado, cada vez mais, no contexto planetário (MORIN, 2003, p. 13-14).

Na mesma perspectiva, Morais (2010, p. 7) discute que "todo conhecer e aprender depende do que acontece no sujeito, [...] depende de tudo aquilo que acontece no ser humano [...] o conhecimento acontece no cotidiano da vida, no viver/conviver". 
Sendo assim, é importante enfatizar a necessidade de também considerar, no currículo, o contexto, a diversidade, as emoções e os interesses dos sujeitos (professores e alunos), em cada momento, em cada aula, a cada dia... as emergências que podem mudar rumos e maneiras de produzir currículos. Tais aspectos, no entanto, nem sempre são valorizados nos currículos prescritos, conforme podemos observar no Quadro apresentado na Figura 2, retirado do currículo previsto para a disciplina de Língua Portuguesa.

Figura 2 - Quadro de gêneros textuais a serem explorados na Língua Portuguesa

QUADRO 2 - GENEROS A SEREM TRABALHADOS EM CADA BIMESTRE NA PRODUÇAO ESCRITA

Ao final de cada BiM. deve ser sarantida a apropriaçäo escrita dos generos selocionados neste quadro

\begin{tabular}{|c|c|c|c|c|}
\hline ANO & $1^{\circ} \mathrm{BIMC}$. & $2^{\circ}$ в।M. & $3^{\circ} \mathrm{BIM}$. & $4^{\circ}$ вам. \\
\hline $1^{\circ}$ & - Lista & - Quadrinha & $\begin{array}{l}\text { - Canoga } \\
\text { - Parienda }\end{array}$ & $\begin{array}{l}\text { - Tirinha } \\
\text { - Legenda }\end{array}$ \\
\hline$r^{r}$ & $\begin{array}{l}\text { - Letra de música } \\
\text { - Pariendo }\end{array}$ & $\begin{array}{l}\text { - Batete } \\
\text { - Roceta }\end{array}$ & $\begin{array}{l}\text { - Convite } \\
\text { - Contos Clossicos }\end{array}$ & - História em Quadrinhos \\
\hline $3^{\circ}$ & $\begin{array}{l}\text { - Anáncio } \\
\text { - Conto classico }\end{array}$ & $\begin{array}{l}\text { - Texto científico } \\
\text { - Fabula }\end{array}$ & $\begin{array}{l}\text { - Lenda } \\
\text { - Históris em Quadrinhos }\end{array}$ & $\begin{array}{l}\text { - Regras de jogo } \\
\text { - Noticia }\end{array}$ \\
\hline $4^{\circ}$ & $\begin{array}{l}\text { - Texto de opinido } \\
\text { - Corta de reclamaçlo }\end{array}$ & $\begin{array}{l}\text { - Texto cientifico } \\
\text { - Historia em Quadrinhos }\end{array}$ & $\begin{array}{l}\text { - Relato pessiool e de } \\
\text { experimento } \\
\text { - Propaganda }\end{array}$ & $\begin{array}{l}\text { - Resurno } \\
\text { - Conto de mistirio }\end{array}$ \\
\hline $5^{\circ}$ & $\begin{array}{l}\text { - Noticia } \\
\text { - Texto de opiniabo }\end{array}$ & $\begin{array}{l}\text { - Conto de misténo } \\
\text { - Resumo }\end{array}$ & $\begin{array}{l}\text { - Texto teatral } \\
\text { - Parddia e Poema }\end{array}$ & $\begin{array}{l}\text { - Causo } \\
\text { - Texto cientifico }\end{array}$ \\
\hline
\end{tabular}

Fonte: CAMPO GRANDE-MS, 2016, p. 10.

Pode-se observar certa rigidez na proposição desse currículo, haja vista a sugestão de que a cada bimestre "deve ser garantida" aos alunos a possibilidade de escrita e leitura dos gêneros literários propostos. Tal critério, a nosso ver, propõe uma linearidade nas ações de alunos e professores nos primeiros anos do Ensino Fundamental, como também pode representar uma valorização do currículo extensivo em detrimento do currículo intensivo.

Ressaltamos que esse é "o nosso olhar" sobre o documento. Cada professor pode interpretá-lo de outros modos, considerando outros conhecimentos, outros documentos, inclusive o que é afirmado no PPP da Escola Municipal X em que realizamos a pesquisa: "esta proposta não apresenta um método rígido no fazer pedagógico". Essa informação nos dá indícios de que os professores podem (re)significar esse documento na ação, em suas práticas de sala de aula, autoeco-organizando-se, até porque, em determinado contexto, os alunos podem manifestar outros interesses e os professores podem optar por explorar outros gêneros literários e textuais, que não os previstos para "aquele bimestre".

E se por distintos motivos do cotidiano da sala de aula, em certo bimestre, não for possível explorar determinado gênero que estava previsto? Por que não flexibilizar essa proposição? O que garante que, se explorados em aula, nessa sequência, os alunos aprenderão a produzir textos, a ler e escrever usando os gêneros textuais indicados? Pensamos ser relevante refletir sobre essas e tantas outras questões. É importante planejar ações a serem desenvolvidas em sala de aula, mas é preciso também considerar e lidar com o acaso, o emergente; é necessário autoeco-organização. 
Acreditamos que a flexibilidade do currículo poderia, dentre outras coisas, caminhar aliada ao contexto e interesses dos alunos. Por exemplo, em relação à escrita, no 10 ano da escola em que realizamos a pesquisa utiliza-se, quase que com exclusividade, a produção de textos com letra "bastão" ${ }^{13}$, em papel e lápis, além de investir na coordenação motora para o traçado das letras com vistas à composição de palavras e textos. É de se considerar, contudo, que para o uso do celular, computador, tablet, lousa digital bastam alguns cliques, toques, para que as letras apareçam na tela, os textos sejam produzidos e palavras sejam escritas sem exigir muita coordenação motora. Neste último caso, a atenção da criança está voltada ao texto que deseja produzir, às palavras que quer usar, constituídas por letras disponíveis no teclado. No primeiro caso, por vezes o foco está no traçado das letras e no tempo considerável para desenhá-las até que componham palavras e textos.

Levando em consideração esse cenário, acreditamos que as tecnologias digitais, se usadas de forma integrada ao currículo, constituem mais uma possibilidade de linguagem a contribuir com/para os processos de ensino e aprendizagem. Isso, no entanto, é complexo, tendo em vista o contexto, a formação dos professores, a estrutura das escolas, os currículos prescritos e em ação (que nem sempre dão conta, e nem precisam, de tudo o que é previsto), os calendários, as situações climáticas, os movimentos políticos, sociais e tantos outros fatores que podem interferir na (re)significação do currículo, na ação.

Vamos continuar problematizando os currículos prescritos... Na busca de documentos que preveem o uso de tecnologias digitais no currículo prescrito para o $1^{10}$ ano, na disciplina de Matemática, por exemplo, encontramos um quadro definido como "Repertório de Cálculo", em que se sugere o uso da calculadora, conforme apresentamos na Figura 3 a seguir.

Figura 3 - Tecnologias presentes no currículo de Matemática

QUADRO 3 - REPERTORIO DE CALCULO

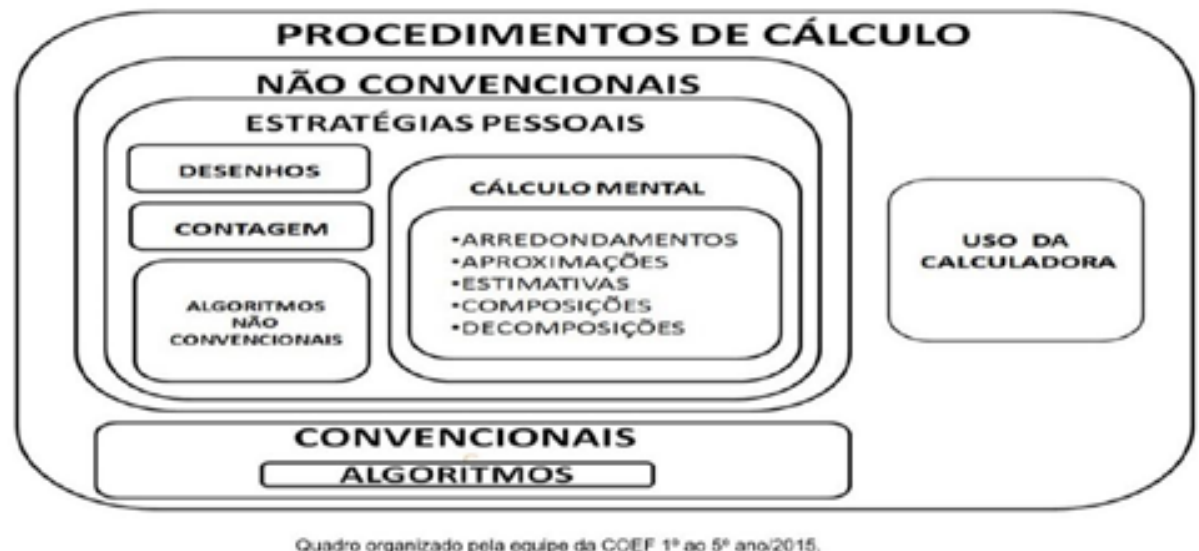

Fonte: CAMPO GRANDE-MS, 2016, p. 23.

\footnotetext{
${ }^{13}$ A letra bastão, também conhecida como letra de "forma", é apresentada aos alunos no início da alfabetização. Trata-se de um estilo de escrita em que os caracteres não estão ligados uns aos outros. 
Podemos observar a sugestão de variadas estratégias para realizar os cálculos (cálculo mental, contagem, desenhos, algoritmos, ...), e o uso da calculadora aparece como um procedimento de cálculo. Ao refletirmos um pouco mais sobre o uso da calculadora no 1 o ano, todavia, ficamos pensando na relação entre o uso dessa tecnologia e os objetivos anunciados, como: contar e comunicar, estabelecer correspondência entre quantidade e sua representação em algarismos e resolver situações-problema de adição e subtração envolvendo situações do contexto familiar.

O emprego da calculadora no $1^{\circ}$ ano pode ser uma possibilidade para explorar questões/conceitos de estimativa, algoritmo; um uso não direcionado à busca de respostas diretas, por exemplo, certo ou errado, mas como entendimento de processo; um pensar as/nas operações. Utilizá-la como mais uma tecnologia (não a única, como está previsto no recorte do documento) pode estimular o brincar, o estimar e o aprender; até porque existem outras tecnologias, tais como softwares, aplicativos, jogos... que os professores podem utilizar e, por meio deles, oportunizar a mobilização dos alunos na produção de conhecimento matemático. Ou seja, há distintos meios de desafiar e instigar os alunos a pensar, calcular, estimar quantidades, brincar, produzir, construir, aprender. A calculadora é apenas um deles. Consideramos que para atender a esses objetivos previstos para o 10 ano é importante investir na integração de outras estratégias, podendo, inclusive, ser o uso de tecnologias digitais.

Dessa forma, considerando o contexto da Cultura digital, pensamos que as tecnologias digitais podem ser utilizadas em aulas; quando conectadas à internet, configuram-se como mais uma possibilidade para complementar, modificar e (re)configurar algumas aulas, e até mesmo possibilitar a (re)significação das disciplinas a partir do que é proposto no currículo prescrito.

Desse modo, consideramos que, ao utilizar tecnologias digitais, como o computador conectado à internet, por exemplo, em aulas, é possível ter um currículo em ação, no qual "abandonamos um tipo de explicação linear por um tipo de explicação em movimento, circular, onde vamos das partes para o todo, do todo para as partes, para tentar compreender um fenômeno" (MORIN, 2014, p. 182). Ressaltamos que a construção do conhecimento complexo não está intimamente ligada ao acesso à internet, mas enfatizamos que este pode vir a ser potencializado, caso esteja alinhado aos objetivos pedagógicos do professor quando opta por uma aula com tecnologias digitais. Além disso, trazemos, neste artigo algumas problematizações que realizamos durante a pesquisa e enfatizamos que estão longe de serem as únicas, pois são apenas recortes de duas disciplinas que compõem o currículo prescrito do 1ㅇano - Língua Portuguesa e Matemática.

A seguir analisamos um recorte de um currículo em ação, de um determinado dia para o qual estava prevista uma aula de Geografia em uma turma de 10 ano. Para procedermos a essa análise, apresentamos a transcrição de parte de uma narrativa da professora do 1 o ano, participante da pesquisa, quando relatou, em uma reunião, sobre essa aula de Geografia que desenvolvera com seus alunos. Aconteceu em sala de aula; a 
professora usou um projetor multimídia e um notebook, conectados à rede de internet wi-fi da escola (conquista financiada pelos professores da escola, como solução emergencial para atender suas necessidades docentes ${ }^{14}$ ).

Inicialmente utilizamos o Google Earth, no qual é possível ver uma projeção do mundo. Os alunos puderam ver a localização do Brasil; eles ficaram enlouquecidos ao ver a neve nos polos, porque parece tudo branco, e perguntavam: - Profe ali que tem a neve? Além disso, visualizamos a África, e eu aproximei a imagem entrando em duas cidades, pois eu queria ver os tipos de moradia. Embora não tenha aparecido muito, pudemos avistar casas e prédios. Também não foi possível avistar a periferia, eu queria ver como são as casas, como são construídas, queria mostrar isso para meus alunos, mas não conseguimos ver. Mesmo assim foi muito legal!

Depois de visitar a África, visitamos Mato Grosso do Sul, e mais especificamente o município de Campo Grande. Para poder aproximar as imagens e mostrar as paisagens mais de perto, utilizamos o Google Maps. Nesse aplicativo eu fui digitando o endereço dos alunos (bairro, rua e o no da casa). Ao avistar o local que aparecia na grande tela projetada na parede, tinha aluno na sala que não sabia que morava a três quadras da casa de um colega. Eles falavam: - Profe, eu já passei por essa casa, eu moro logo ali pra frente, vai pra frente. E eu ia caminhando com o bonequinho que aparece no aplicativo, e eles iam me orientando, iam interagindo, dizendo: - vai indo mais, agora vira. E eu perguntava: - virar para a esquerda ou para a direita? Eles diziam: - pra cá (apontando para um lado). Eu dizia: - esquerda, e virava... E assim chegávamos na casa que estávamos procurando.

Foi uma atividade muito legal! Trabalhei até lateralidade. Depois que chegava na casa do aluno eu confirmava com o aluno o endereço. E eles falavam: - mas profe, $o$ muro não está mais assim. E eu dizia: - estão vendo a data que tem ali? As fotos foram tiradas em 2007. De 2007 até agora (2017) foram quantos anos? - 10 anos. Mudou muita coisa no período de 10 anos. Eu continuei perguntando: - o que tinha nesse lugar antes? - Profe, era mato, agora tem uma casa (comentava um aluno).

A partir disso eu comentava que tudo vai mudando, que o ser humano vai modificando o ambiente. Nessa aula tive a oportunidade de ir linkando vários conteúdos, e discutir com os alunos, não ficando nas gavetinhas. Os alunos puderam ver que usamos vários conteúdos em uma aula, usamos matemática, usamos português, ... A partir do uso da internet, nesse aplicativo, pudemos ver o nome da rua escrito na placa, e no asfalto também fica escrito o nome da rua, e os alunos estavam tentando ler o nome da rua. Muito legal! Os alunos me surpreenderam demais!

\footnotetext{
${ }^{14}$ Poderíamos perguntar: Por que professores precisam pagar por um recurso que deveria ser fornecido pelo Estado? Esse é mais um ponto que precisa ser discutido quando investigamos processos de integração de cultura digital ao currículo: Por que ainda muitas pessoas consideram que para se ter uma escola basta uma árvore, um professor e alunos? Como problematizar questões atuais da cultura digital, produzir nesta cultura, sem ter acesso à tecnologia digital em escolas constituídas em locais em que esta é uma cultura presente?
} 


\section{Professora do 10 ano}

A partir desse recorte de narrativa podemos observar uma possibilidade de currículo em ação que transcende o prescrito. É um currículo em ação em que tabelas e quadros foram tecidos conjuntamente, em uma ordem que obedecia ao fluxo de curiosidade e construção de conhecimento das crianças, integradas à rede, viajando/passeando e conhecendo diferentes lugares e tempos, seus endereços... juntos, mas, sem sair fisicamente da escola. Essa aula possibilitou produzir algo que foi diferente do planejado, do escrito, do proposto, do prescrito; proporcionou vivenciar um currículo produzido por quem estava ali, naquele lugar, com aquelas pessoas, com aquelas curiosidades e conhecimentos, sem deixar de estar integrado a outros documentos, espaços, pessoas.

Esse movimento, esse currículo em ação, pode ser considerado uma autoeco-organização da professora em sua relação com um currículo prescrito, tendo em vista o contexto em que atuava naquele momento. É importante lembrar que naquele momento essa prática aconteceu daquele jeito, com suas singularidades, mas que não é o único, uma vez que, se a professora tentar repetir a mesma ação com outra turma, certamente será diferente, porque será outro momento e, assim como acontecerá com ela, os interesses podem ser outros e a participação dos alunos também. Moraes (2010, p. 12) corrobora esse fato quando anuncia que é "no cotidiano da sala de aula, a partir do currículo nutrido pela complexidade, que são tecidas as redes de significados compartilhados por diferentes sujeitos, mediante as quais são construídos os conhecimentos".

Nesse movimento, nessa ação, destacamos que a flexibilidade e a autonomia da professora fizeram muita diferença na discussão dos conteúdos que foram surgindo durante a aula. Evidenciamos, ainda, que as tecnologias digitais (projetor multimídia, internet, aplicativos...) oportunizaram esse processo, contribuindo como mais uma possibilidade de linguagem para promover as tessituras das redes de conhecimento. Isso pode ser observado no movimento de (re)construção da aula (que inicialmente fora planejada para discutir conteúdos de Geografia); ao integrar aplicativos da internet ao projetor multimídia em sala de aula, a professora possibilitou discutir, também, conhecimentos de Matemática, Língua Portuguesa, História, vida...

Vamos problematizar: essa aula poderia ser vivenciada sem o aplicativo acessado pela internet e projetado em uma parede da sala de aula? O que podemos afirmar é que as tecnologias digitais usadas estavam integradas ao currículo, pois sem elas não seria possível visitar tantos locais e endereços em tão pouco tempo, sem sair do espaço físico da escola; talvez muitas questões discutidas na aula poderiam não surgir se fossem exploradas de outra forma: questões de lateralidade, mudanças no meio ambiente (planeta, Estado, município, bairro), subtração na ideia aditiva ao problematizar o tempo decorrido desde o dia em que foi feita a captura de imagens pelo Satélite, importância dos endereços e da escrita, ...).

É interessante evidenciar, ainda, que nessa aula os alunos foram considerados sujeitos pensantes, autores e coautores de sua própria história, moradores daqueles bairros em Campo Grande, interagindo com os colegas e a professora, reconhecendo seu lugar no mundo, construindo e (re)construindo conhecimentos. 
Assim, essa prática, segundo nosso olhar, representa o quanto a complexidade dos conteúdos pode envolver os alunos e fazer com que eles compreendam o microespaço (bairro) em que vivem, integrado ao mundo (Planeta Terra); representa a importância de saber ler, escrever, representar, localizar-se no espaço e tempo, na história... Tal prática corrobora o que Pascal já dizia: "só posso compreender o todo se conheço, especificamente, as partes, mas só posso compreender as partes se conheço o todo" (MORIN, 2014, p. 181).

\section{ALGUMAS REFLEXÕES FINAIS E INICIAIS...}

A partir das problematizações propostas neste artigo, podemos considerar que o currículo prescrito aqui analisado ainda evidencia a fragmentação das disciplinas e conteúdos, que "convidam" nossos alunos a vivenciarem, nas escolas, uma cultura que destoa da cultura que vivenciam fora dela. Nessa perspectiva, acreditamos que a prática realizada com o uso da internet em sala de aula oportunizou, na ação, a vivência de um currículo não prescritível, mas que se autoeco-organiza também na relação com currículos prescritos.

Percebemos, igualmente, que partilhar, produzir, construir, enfim, vivenciar a integração de aulas à Cultura Digital nos convida à experimentação e problematização do(s) currículo(s). Nesse movimento, buscamos provocar diálogos iniciais, que precisam/podem ser continuamente (re)alimentados no campo da Educação, principalmente quando pensamos que os currículos propostos nas escolas devem atender, também, ao que é vivenciado na sociedade, na cultura, e às necessidades de formação das crianças.

A escrita deste artigo, orientadas pelos estudos da complexidade, oportunizou também uma reorganização do que pensamos e fazemos na/da escola. Estariam essas questões muito além do nosso alcance? Precisaríamos de mais professores, coordenadores, diretores, pais, alunos, pesquisadores, ..., se autoeco-organizando nos espaços escolares? Como oportunizar a vivência de mais currículos em ações nas escolas, em uma dinâmica complexa, considerando a necessidade de investimento em tecnologias digitais que tem ajudado a produzir uma cultura que é também digital? E quanto aos professores e gestores? Como investir em currículos de formação inicial e continuada em serviço que atendam às necessidades de cada um e de cada grupo? É... respostas, receitas, soluções não temos, e nem recomendamos! Apenas sugerimos que experienciem o exercício de autoeco-organizar currículos.

Currículos que não valorizem as disciplinas separadamente, mas que considerem diferentes contextos, interesses e situações; currículos que tenham abertura e flexibilidade para dialogar diante das bifurcações que a "realidade multidimensional, sempre em movimento" nos impõe, pois, de acordo com Moraes (2010, p. 12), é "insustentável aquele pensamento que recorta, isola, mutila, fragmenta os objetos do conhecimento e a realidade pesquisada e que ainda continua presente na sala de aula e nos processos de reorganização curricular"; currículos que considerem a incompletude dos processos educacionais, que produzam movimentos, que considerem diferentes ações, em movimentos recorrentes e recursivos, que possam ser problematizados, questionados... 
Referimo-nos a currículos que possuem identidade perante a escola, os professores, os alunos, a comunidade; que estejam em constante construção, inacabados, construídos individual e socialmente; (re)construídos a partir das redes de interação, considerando os meios como ambiente de mudança e transformação, no qual se consideram os sujeitos pensantes. E mais: currículos que oportunizam a professores e alunos interagirem sem aprisionar e fragmentar a realidade em verdades únicas, compreendendo o conhecimento como em movimento, inacabado, transitório, em constante construção...

Por fim, pensamos em currículos nos quais a pluralidade cultural, a multirreferencialidade, a diversidade e as subjetividades sejam consideradas; currículos flexíveis, que podem ser revisitados, reconstruídos e transformados em sala de aula, de acordo com as necessidades, respeitando os tempos de cada sujeito e que todos (professores, alunos, pais, coordenação) possam ser considerados autores e coautores dos processos educacionais, da cultura, de si mesmos. Currículos esses que possibilitem produzir conhecimentos a partir de movimentos autoeco-organizadores nas relações com os outros e com o meio, com as culturas e tecnologias por elas produzidas.

\section{AGRADECIMENTOS}

À Fundect/Capes por financiar esta pesquisa. Ao apoio da Coordenação de Aperfeiçoamento de Pessoal de Nível Superior - Brasil (Capes) - Código de Financiamento 001".

\section{REFERÊNCIAS}

ALMEIDA, M. E. B.; VALENTE, J. A. Tecnologias e currículo: trajetórias convergentes ou divergentes? São Paulo: Paulus, 2011.

CAMPO GRANDE-MS. Orientações curriculares: Ensino Fundamental 1o ao 5ㅇa․ ano. Secretaria Municipal de Educação. Prefeitura de Campo Grande, 2016.

CAMPO GRANDE-MS. Projeto Político Pedagógico-PPP. Escola Municipal X. Campo Grande, 2015.

HEINSFELD, B. D.; PISCHETOLA, M. Cultura digital e educação, uma leitura dos estudos culturais sobre os desafios da contemporaneidade. Revista Ibero-Americana de Estudos em Educação, Araraquara, v. 12, n. esp. 2, p. 1.349-1.371, ago./2017. Disponível em: http://dx.doi.org/10.21723/riaee.v12.n.esp.2.10301. Acesso em: 15 set. 2018.

KENSKI, V. M. Educação e tecnologias: o novo rumo da informação. 8. ed. Campinas, SP: Papirus, 2012.

MORAES, M. C. Complexidade e currículo: por uma nova relação. Polis [on-line], 25, 2010. Disponível em: https://journals.openedition.org/polis/573. Acesso em: 7 out. 2018.

MORIN, E. A cabeça bem-feita: repensar a reforma, reformar o pensamento. 8. ed. Rio de Janeiro: Bertrand Brasil, 2003.

MORIN, E. Ciência com consciência. 16. ed. Rio de Janeiro: Bertrand Brasil, 2014.

PRENSKY, M. Digital Natives, Digital Immigrants, Part 1. On The Horizon, v. 9, p. 3-6, 2001. Disponível em: http://dx.doi.org/10.1108/10748120110424816. Acesso em: 23 jul. 2019.

RODRIGUES, A.; ALMEIDA, M. E. B.; VALENTE, J. A. Currículo, narrativas digitais e formação de professores: experiências da Pós-Graduação à escola. Revista Portuguesa de Educação [on-line], 30, p. 61-83, jan./ jun. 2017. Disponível em: https://www.redalyc.org/pdf/374/37451307004.pdf. Acesso em: 23 jul. 2019.

SILVA, T. T. Documentos de identidade: uma introdução às teorias do currículo. 2. ed. Belo Horizonte: Autêntica, 2005. 